\title{
Cheyne-Stokes Respiration and Prognosis in Neurocritical Patients
}

\author{
Tae-Joon Kim ${ }^{1}$, Dukyong Yoon ${ }^{2,3}$, Jung Hwan Kim ${ }^{1}$, Jong-Hwan Jang ${ }^{2}$ \\ ${ }^{1}$ Departments of Neurology and ${ }^{2}$ Biomedical Informatics, Ajou University School of Medicine, Suwon, \\ ${ }^{3}$ Department of Biomedical Sciences, Ajou University Graduate School of Medicine, Suwon, Korea \\ 체인-스토크스 호흡이 신경계 중환자의 예후에 미치는 영향 \\ 김태준 ${ }^{1}$, 윤덕용 $^{2,3}$, 김정환 ${ }^{1}$, 장종환 $^{2}$ \\ 아주대학교 의과대학 신경과학교실, ${ }^{1}$ 의료정보학교실, ${ }^{2}{ }^{2}$ 아주대학교 대학원 의생명과학과 ${ }^{3}$
}

Received June 1,2020

Revised June 17, 2020

Accepted June 17, 2020

Address for correspondence

Tae-Joon Kim, MD

Department of Neurology,

Ajou University

School of Medicine,

164 World cup-ro, Yeongtong-gu,

Suwon 16499, Korea

Tel: +82-31-219-5090

Fax: $+82-31-219-5178$

E-mail: tjkim23@ajou.ac.kr
Objectives: Cheyne-Stokes respiration (CSR) is frequently found in critically ill patients and is associated with poor prognosis. However, CSR has not been evaluated in neurocritical patients. This study investigated the frequency and prognostic impact of CSR in neurocritical patients using biosignal big data obtained from intensive care units. Methods: This study included all patients who received neurocritical care at the tertiary hospital from January 2018 to December 2019. Clinical information and biosignal data of intensive care units were used and analyzed. The respiratory curve was visually assessed to determine whether CSR and obstructive sleep apnea (OSA) were present, and a heart rate variability (HRV) was obtained from the electrocardiogram. Results: CSR was confirmed in 166 of 406 patients (40.9\%). Patients with CSR were older, had a higher frequency of cardiovascular risk factors as well as heart failure, and had a poor outcome (modified Rankin scale $\geq 4$ ). As a result of multiple regression analysis adjusted for other variables, CSR was significantly associated with poor outcome with an odds ratio of 2.27 times higher ( $95 \%$ confidence interval $1.25-4.14, p=0.007)$. HRV analysis demonstrated that CSR and OSA had distinct autonomic characteristics. Conclusions: This study first revealed the substantial frequency of CSR in neurocritical patients and suggests that it can be used as a predictor of poor prognosis in neurocritical care.

J Sleep Med 2020;17(1):84-92

Key Words: Cheyne-Stokes respiration, Critical illness, Prognosis.

\section{서 론}

체인-스토크스 호흡(Cheyne-Stokes respiration, CSR)은 증가-감소 양상으로 과호흡과 무호흡/저호흡이 주기적으로 반복되는 호흡 양상을 말한다. ${ }^{1} \mathrm{CSR}$ 은 중추성수면무호흡 (central sleep apnea, CSA)의 가장 흔하고 대표적인 형태로, 기도가 물리적으로 막히는 폐쇄성수면무호흡(obstructive sleep apnea, OSA)과 달리 CSA는 수면 중 호흡 노력이 저하 되거나 없어져 발생한다..$^{2-4} \mathrm{CSR}$ 은 뇌질환, 심장질환, 폐질환 을 가진 환자에서 흔히 나타나며 특히 심한 심부전 환자의

This is an Open Access article distributed under the terms of the Creative Commons Attribution Non-Commercial License (https://creativecommons.org/licenses/by-nc/4.0) which permits unrestricted non-commercial use, distribution, and reproduction in any medium, provided the original work is properly cited.
약 60\%에서 동반된다고 알려졌다. ${ }^{5} \mathrm{CSR}$ 이 있을 경우 예후가 좋지 않다고 알려져 있는데, 최근 CSR 환자에서 적응형 서보 환기(adaptive servo ventilation) 치료가 예후 개선에 도움이 되지 않았다는 연구가 발표된 이후 결과 해석에 따른 논란이 많았다. ${ }^{6-9}$ 가장 큰 쟁점은 CSR이 치료가 필요한 경우인지 또는 장기적인 생리적인 반응에 지나지 않는지에 대한 논쟁 으로 ${ }^{10}$ 치료가 필요한 환자군에 대한 올바른 설정이 이와 같 은 논란에 해답이 될 수 있겠다.

중환자실에 입원하는 환자에서 CSR에 대한 연구는 그리 많지 않고 다양한 빈도로 보고되었다. 급성 심혈관질환 중환 자의 경우 한 연구에서는 약 $34 \%$ 에서 CSR이 확인되었던 반 면, 다른 연구에서는 약 $82 \%$ 에서 CSR을 포함한 CSA가 발 견되었다. ${ }^{11,12}$ 심전도 신호를 이용하여 CSR 또는 주기적 호 
흡을 확인한 최근 연구에서는 전체 중환자의 약 $84 \%$ 에 이르 는 높은 빈도가 확인되었고 중증도가 불량한 예후와 관계가 있음을 보였다. ${ }^{13}$ 이러한 CSR 빈도는 환자군과 연구한 호흡 양상 및 연구 방법의 차이에 기인한 것으로 판단된다. 신경 계 질환 중에서는 뇌졸중에서 CSR의 빈도가 약 20 40\%를 차지한다는 것이 보고되었으며, 뇌전증에서는 돌연사(sudden unexplained death in epilepsy)와 관련성이 보고되었 다. ${ }^{14-16}$ 하지만 중환자실에 입실하는 신경계 질환 환자에서 $\mathrm{CSR}$ 의 빈도나 예후와의 연관성은 지금까지 연구된 바 없다.

본 연구에서는 중환자실 치료를 받은 신경계 질환 환자를 대상으로 호흡 양상을 확인하기 위해 중환자실 생체신호 빅 데이터를 이용하였다. 그 결과 신경계 중환자 전체에서 CSR 의 빈도를 확인하였고 임상 지표와 함께 예후와의 연관성을 분석하였다. 추가적으로 CSR과 예후와의 관계에 대한 설명 을 위해 CSR이 자율신경계에 미치는 영향을 심박변이지수 (heart rate variability, HRV)로 알아보았다.

\section{방 법}

본 연구는 2018년 1월부터 2019년 12월까지 아주대학교 병원 신경과에 입원하여 중환자실 치료를 받은 모든 환자를 대상으로 하였다. 아주대학교병원은 2017년부터 중환자실 생체신호를 전향적으로 수집하고 있다. 이 연구 과정과 중환 자실 생체신호 수집은 각각 아주대학교병원 윤리심의위원회 의 승인을 받았다(IRB no. AJIRB-MED-MDB-20-136; no. AJIRB-MED-MDB-16-155).

환자 선정 기준으로는 1) 18세 이상의 성인 남녀, 2) 입원 3 일 이내 중환자실에 입실한 초기 중증 환자, 3) 22시부터 다 음 날 6시까지의 자가 호흡 데이터가 최소 하루 이상 가능한 환자로 정했다. 신경과 입원 환자들은 신경계 중환자실, 응급 중환자실, 내과계 중환자실, 또는 외과계 중환자실에 입원한 경우를 모두 포함하였다. 신경과에 입원하여 3일 이내 중환 자실에 입실한 초기 중증 성인 환자는 총 495명이었고 그중 89명은 하루 이상의 자가 호흡 데이터가 없어 제외되어 총 406명의 환자에 대해 분석을 시행하였다. 환자의 임상 정보 로 인구학적 정보, 기저 질환, 진단, 중환자실 입실 시 acute physiology and chronic health evaluation-II(APACHE-II) 점수, 기관 삽관 유무, 기관 절개술 유무, 입원 기간, 중환자실 체류 기간 및 퇴원 시 수정 랭킨 점수(modified Rankin scale, $\mathrm{mRS}$ )를 후향적으로 수집했다. 기저 질환은 고혈압, 당뇨, 심 혈관질환, 심방세동, 폐질환(결핵, 간질성 폐질환, 만성 폐색 성 폐질환), 뇌졸중, 신경퇴행성질환(파킨슨, 치매)을 포함했 다. 진단은 다음과 같이 5 개로 분류하였다: 뇌혈관질환(neu- rovascular disease), 감염/염증질환(infection/inflammation), 경련성질환(seizure), 척수/신경/근육질환(cord/nerve/muscle), 대사성/독성/종양질환(metabolic/toxic/neoplasm). 연 구에 포함된 대상자들 중 수면다원검사를 시행한 환자의 검 사 결과를 확인하였고 본 연구에서 판단한 호흡과 비교하였 다. 입원 중 경흥부심초음파를 시행한 환자들에서는 좌심실 박출계수(left ventricular ejection fraction, LVEF)를 수집하 였고, $\mathrm{LVEF}$ 가 $45 \%$ 이하인 환자들은 심부전으로 판단하였 다. $\mathrm{mRS}$ 가 4점 이상인 경우 불량한 예후로 정의하였다.

중환자실 생체신호 빅데이터는 아주대학교의료원 의료정 보학과에서 기획득한 자료를 사용했다. ${ }^{17}$ 가용한 생체신호는 호흡, 심전도, 맥파(photoplethysmography), 혈압을 포함하 며, 생체신호의 변동을 수치화한 자료로, 본 연구에서는 호흡 과 심전도 데이터를 분석했다. 데이터는 중환자실의 $\mathrm{BSM}-$ 1753(Nihon Kohden, Tokyo, Japan) 또는 IntelliVue MP70 (Philips Medical Systems, Andover, MA, USA) 모니터 장 비로부터 얻어졌고 표본 추출률(sampling rate) $125 \mathrm{~Hz}$ 로 저 장된 수치를 분석에 이용하였다. 호흡 데이터는 흥곽의 심전 도 전극에서 얻어진 임피던스를 이용해 각 장비에서 이차적 으로 얻어진 신호로 일반적으로 중환자실 감시에 사용하는 신호다. 호흡 신호를 10 분 간격으로 시각화한 후 임상 정보 가 가려진 조건에서 신경과 전문의가 수면호흡장애 여부를 판단하였다. CSR은 미국수면학회의 진단기준(American Academy of Sleep Medicine criteria, version 2.6)의 기준을 이용하였으며 본 연구에 맞게 일부 변형하여 다음과 같이 정 의했다. ${ }^{18}$

A. 호흡 곡선에서 판단되는 과호흡과 무호흡/저호흡이 반 복되어 나타나며 증가-감소(crescendo and decrescendo) 양 상으로 변화하고 각 사이클의 길이는 40초 이상임.

B. 분석된 날의 22 시부터 다음 날 6 시까지 1 시간당 5 회 이 상의 증가-감소 호흡 양상이 나타남.

분석된 날은 중환자실 입원 중 10 일 이내로 자가 호흡 데 이터가 가능한 날로 정하였다. OSA 또한 흥곽 호흡 신호를 이용해 판단하였다. 심전도 유래 호흡(electrocardiogramderived respiration)을 이용해 높은 정확도로 OSA를 판단한 기존 연구들이 있었으며, 호흡 모양이 여러 변수 중 높은 정 확도를 보임을 확인한 바 있다. 19,20 본 연구에서는 CSR이 아 닌 호흡 신호의 변화 중, 호흡 진폭의 단속적인 저하가 나타 나며, 그 시각적 양상이 일반적인 수면다원검사에서 전형적 으로 보이는 폐쇄성무호흡 또는 폐쇄성저호흡으로 판단되 고, 분석된 날의 22 시부터 다음 날 6 시까지 1 시간당 5 회 이상 나타날 때 OSA로 판단하였다. ${ }^{21}$ 대표적인 CSR과 OSA의 호 흡 양상은 그림과 같다(Fig. 1). 호흡 데이터는 Python ver- 

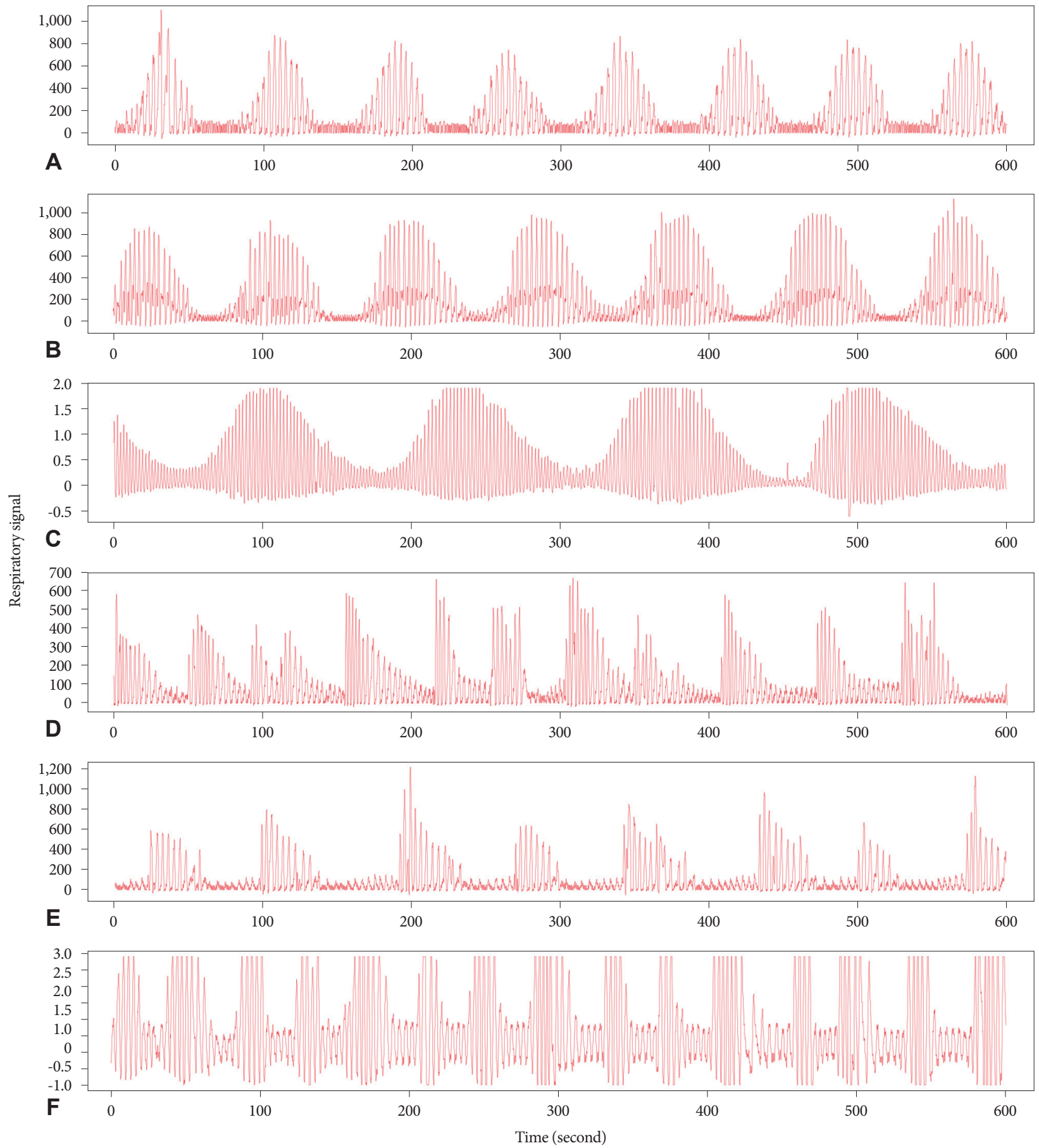

Figure 1. (A-C) Characteristic respiratory signal of Cheyne-Stokes respiration obtained from a 72-year-old female, a 79-year-old female, and an 89-year-old male. (D-F) Characteristic respiratory signal of obstructive sleep apnea obtained from a 53-year-old male, a 77-yearold female, and a 65-year-old male. All the patients had an ischemic stroke.

sion 3.8(Python Software Foundation, Beaverton, OR, USA)을 이용하여 시각화하였다.

심전도 데이터로부터 HRV를 구하였다. HRV는 1) CSR만 있는 환자, 2) OSA만 있는 환자, 3) CSR과 OSA가 모두 없는 환자를 나이 및 성별로 일치하여 각 23명에 대해 데이터를 분석하였다. 심방세동 또는 심부전이 있는 환자는 포함되지
않았다. HRV를 비교 분석하는 과정은 다음과 같이 Szollosi 등의 연구 방법을 이용하였다. ${ }^{22} \mathrm{CSR}$ 과 OSA 환자에서는 안 정호흡, $\mathrm{CSR}, \mathrm{OSA}$ 조건에 대해, 모두 없는 환자에서는 정상 호흡에 대해 HRV를 분석할 구간을 선택하였는데, 22시부터 다음 날 6시 내에서 잡음(artifact)이 최소인 10분을 각각 택 하였다. 안정호흡 또는 정상호흡은 10 분 동안 호흡 중 호흡 
곡선의 진폭이 $5 \%$ 이내로 변동이 거의 없는 부분을 택했으 며 세 군에서 모두 선택했고, CSR과 OSA의 안정호흡은 합 쳐서 분석했다. Kubios HRV Standard version 3.3.1(Kubios Oy, Kuopio, Finland)을 이용하여 HRV의 시간 영역 및 주 파수 영역 변수들을 구했다. 시간 영역 변수들은 심전도에서 인접한 $\mathrm{QRS}$ 복합체의 $\mathrm{R}$ 과 연속된 다음 $\mathrm{R}$ 사이의 간격을 뜻 하는 $\mathrm{NN}$ 간격 $(\mathrm{ms}), 60,000 / \mathrm{NN}$ 간격으로 계산되는 heart rate (/min), NN 간격의 표준편차인 standard deviation of $\mathrm{NN}$ interval, 인접한 $\mathrm{NN}$ 간격의 차이에 대한 제곱의 합을 평균 하여 제곱근을 구한 root mean square of the successive differences(RMSSD), 연속적인 NN 간격의 차이가 $50 \mathrm{~ms}$ 를 초과하는 NN 간격의 개수를 백분율로 나타낸 proportion of successive RR intervals(pNN50)를 포함했다. ${ }^{23}$ 주파수 영 역 중 very low frequency(VLF) 대역은 $0.00 ~ 0.04 \mathrm{~Hz}$, low frequency(LF) 대역은 $0.04 \sim 0.15 \mathrm{~Hz}$, high frequency(HF) 대역은 $0.15 \sim 0.40 \mathrm{~Hz}$ 에서 분석을 시행하였다. 각 대역 주파 수 파워 $\left(\mathrm{ms}^{2}\right)$ 를 자연 로그로 변환하여 수치를 표시하거나, 전체 주파수 파워에 대한 백분율을 구하였다. 또한 $\mathrm{LF}$ 파워 대비 $\mathrm{HF}$ 파워 비율 $(\mathrm{LF} / \mathrm{HF})$ 을 구하였다.

CSR 유무에 따라 임상 지표를 통계적으로 비교하였다. 연 속형 변수는 평균과 표준편차로, 범주형 변수는 수와 백분율 로 표시하였다. 연속변수는 Student's t-test를 이용했고 범주 형 변수는 Chi-square test나 Fisher test를 이용했다. CSR이 환자의 퇴원 시 예후에 미치는 영향은 다중회귀분석(multiple binary logistic regression)으로 분석하였다. 단변량분석(univariate analysis $)$ 에서 불량한 예후와 관련 있었던 $(p<0.1)$ 요 인들을 다중회귀분석의 독립변수들로 투여하였고, 독립변 수들 간에는 다중공선성이 없음을 확인하였다. 통계 분석은 SPSS statistics version 25.0(IBM Corp., Armonk, NY, USA) 를 사용하였다.

\section{결 과}

전체 406명 중 CSR이 있었던 환자는 166명으로 40.9\%였 다. 모든 환자 및 CSR 여부에 따른 환자군의 임상 정보를 Table 1에 요약하였다. CSR군은 CSR이 없던 군에 비해 나 이가 많았으며(73.7 \pm 11.4 세 vs. $58.4 \pm 17.3$ 세, $p<0.001$ ), 성별 은 통계적인 차이가 없었다(여성, $32.5 \%$ vs. $37.9 \%, p=0.293$ ). $\mathrm{CSR}$ 군에서 고혈압, 당뇨, 심혈관질환, 심방세동, 신경퇴행성 질환의 빈도가 높았으나 폐질환, 뇌졸중 병력은 유의한 차이 가 없었다. LVEF는 CSR군에서 유의하게 낮았으며, LVEF가 $45 \%$ 이하인 심부전 환자도 많았다( $14.4 \%$ vs. $6.3 \%, p=0.031$. $\mathrm{OSA}$ 는 전체 환자 중 $35.0 \%$ 에서 확인되었으며, CSR군과
$\mathrm{CSR}$ 이 없던 군에서 OSA의 빈도는 통계적인 차이가 없었다. 입원 목적 진단 중 뇌혈관질환의 빈도(67.2\%)가 가장 높았 으며 CSR군에서 뇌혈관질환의 빈도(81.3\%)가 더 높았다. $\mathrm{APACHE}-\mathrm{II}$ 점수는 CSR군이 더 높았으나, 기관 삽관 유무, 기관 절개술 유무, 입원 기간, 중환자실 체류 기간은 두 군 간 에 유의한 차이가 없었다. $\mathrm{mRS}$ 는 CSR군에서 유의하게 높았 으며, mRS 4 이상인 불량한 예후도 유의하게 많았다 $(56.0 \%$ vs. $29.2 \%, p<0.001)$.

전체 대상자 중 2명이 수면다원검사를 시행하였다. 그중 한 명은 뇌전증중첩증 진단하에 입원한 75세 남환으로 17일 간 중환자실에서 치료받았고, 중환자실에서 일반병실로 전 실한 당일 수면다원검사를 시행한 후 CSR이 있는 CSA를 진 단하였던 환자였다. 다른 한 명은 좌측 중대뇌동맥 영역 뇌 경색을 진단받은 42세 남환으로 2일간 중환자실 치료를 받았 으며, 일반병실로 전실한 다음날 수면다원검사를 시행하여 severe OSA를 진단했던 환자였다. 두 환자의 호흡 곡선과 수 면다원검사 중 대표적인 부분을 Fig. 2에 표시하였다.

진단에 따라 CSR이 예후에 미치는 영향이 다른지 확인하 기 위해 각 진단 분류별 예후를 확인해 보았다(Table 2). 뇌 혈관질환에서 CSR이 있는 경우는 없는 경우에 비해 불량한 예후가 유의하게 높은 빈도로 확인되었다 $58.5 \%$ vs. $32.6 \%$, $p<0.001)$. 뇌혈관질환 외의 경우에도 CSR은 예후의 안 좋은 인자로 확인되었다( $45.2 \%$ vs. $24.5 \%, p=0.041)$. 감염/염증질 환에서는 통계적 유의성이 확인되었지만 그 외의 질환 분류 들에서는 적은 환자 수로 인해 통계적인 비교가 어려웠다.

불량한 예후에 영향을 미치는 임상 요인을 확인하기 위해 각 변수들에 대해 단변량분석을 시행했으며, $p$ 값이 0.10 이 하인 독립변수들을 다중회귀분석에 투입하였다(Table 3). 그 결과 CSR[odds ratio(OR)=2.27(1.25-4.14), $p=0.007$ 과 여성 [OR=2.42(1.40-4.21), $p=0.002]$ 이 다른 변수들을 보정했을 때에도 불량한 예후와 유의한 관계가 있는 변수였다. 심부전 대신 LVEF를 독립변수로 사용하거나, 심부전과 LVEF 변 수 없이 분석을 시행해도 같은 유의한 결과를 보였다.

$\mathrm{CSR}$ 이 자율신경계에 미치는 영향을 조사하기 위해 CSR과 OSA 각 23명, 그리고 CSR이나 OSA가 모두 없는 23명의 환 자에서 성별, 나이를 일치하여 HRV를 분석하였다(Table 4). $\mathrm{CSR}$ 또는 OSA의 안정호흡에서 HRV 변수는 유의한 차이가 없었고, 정상호흡과도 통계적인 차이가 없었다. 안정호흡 또 는 정상호흡을 기준치로 정하여 CSR과 OSA를 각각, 그리고 서로 비교하였다. CSR은 OSA에 비해 RMSSD와 pNN50 값 이 유의하게 컸으며 안정호흡은 두 군의 중간에 해당하는 값 을 보였다. CSR에서 전반적으로 주파수 파워가 저주파 대역 에서 절대값이 커졌는데, CSR보다 OSA가 극저주파수 대역 
Table 1. Demographic and clinical characteristics according to the presence of CSR

\begin{tabular}{|c|c|c|c|c|}
\hline \multirow{2}{*}{ Parameter } & \multicolumn{3}{|c|}{ Number $(\%)$ or mean \pm SD } & \multirow{2}{*}{$p$} \\
\hline & All patients $(n=406)$ & $\operatorname{CSR}(n=166)$ & No CSR $(n=240)$ & \\
\hline Age, year & $64.7 \pm 16.9$ & $73.7 \pm 11.4$ & $58.4 \pm 17.3$ & $<0.001^{*}$ \\
\hline Sex, female & $145(35.7)$ & $54(32.5)$ & $91(37.9)$ & 0.293 \\
\hline Hypertension & $212(52.2)$ & $106(63.9)$ & $106(44.2)$ & $<0.001^{*}$ \\
\hline Diabetes & $103(25.4)$ & $53(31.9)$ & $50(20.8)$ & $0.015^{*}$ \\
\hline Coronary artery disease & $24(5.9)$ & $15(9.0)$ & $9(3.8)$ & $0.032 *$ \\
\hline Atrial fibrillation & $89(21.9)$ & $64(38.6)$ & $25(10.4)$ & $<0.001^{*}$ \\
\hline Heart failure $(\mathrm{LVEF} \leq 45 \%)$ & $29(10.3)$ & $20(14.4)$ & $9(6.3)$ & $0.031^{*}$ \\
\hline LVEF, \% ${ }^{\dagger}$ & $63.3 \pm 12.6$ & $60.8 \pm 14.0$ & $65.8 \pm 10.5$ & $0.001^{*}$ \\
\hline Lung disease & $27(6.7)$ & $12(7.2)$ & $15(6.2)$ & 0.691 \\
\hline Previous stroke & $76(18.7)$ & $37(22.3)$ & $39(16.2)$ & 0.154 \\
\hline Neurodegenerative disease & $26(6.4)$ & $16(9.6)$ & $10(4.2)$ & $0.038^{*}$ \\
\hline OSA & $142(35.0)$ & $56(33.7)$ & $86(35.8)$ & 0.674 \\
\hline Diagnosis & & & & $<0.001^{*}$ \\
\hline Neurovascular disease & $273(67.2)$ & $135(81.3)$ & $138(57.5)$ & \\
\hline Infection/inflammation & $66(16.3)$ & $18(10.8)$ & $48(20.0)$ & \\
\hline Seizure & $53(13.1)$ & $10(6.0)$ & $43(17.9)$ & \\
\hline Cord/nerve/muscle & $7(1.7)$ & 0 & $7(2.9)$ & \\
\hline Metabolic/toxic/neoplasm & $7(1.7)$ & $3(1.8)$ & $4(1.7)$ & \\
\hline APACHE-II score & $11.3 \pm 6.6$ & $12.3 \pm 6.1$ & $10.6 \pm 6.8$ & $0.009^{*}$ \\
\hline Intubation & $66(16.3)$ & $27(16.3)$ & $39(16.2)$ & $>0.999$ \\
\hline Tracheostomy & $13(3.2)$ & $2(1.2)$ & $11(4.6)$ & 0.083 \\
\hline Hospital day & $18.7 \pm 15.4$ & $18.6 \pm 13.0$ & $18.9 \pm 16.8$ & 0.842 \\
\hline ICU day & $8.6 \pm 10.6$ & $9.0 \pm 9.3$ & $8.3 \pm 11.4$ & 0.676 \\
\hline $\mathrm{mRS}$ at discharge in median [IQR] & $3[1-4]$ & $4[2-5]$ & $2[1-4]$ & $<0.001^{*}$ \\
\hline Poor outcome (mRS $\geq 4)$ & $163(40.1)$ & $93(56.0)$ & $70(29.2)$ & $<0.001^{*}$ \\
\hline
\end{tabular}

*statistical significance $(p<0.05)$, ${ }^{L}$ LVEF values were available in 282 patients who underwent a transthoracic echocardiogram. SD: standard deviation, CSR: Cheyne-Stokes respiration, LVEF: left ventricular ejection fraction, OSA: obstructive sleep apnea, APACHE-II: acute physiology and chronic health evaluation-II, ICU: intensive care unit, mRS: modified Rankin scale, IQR: interquartile range

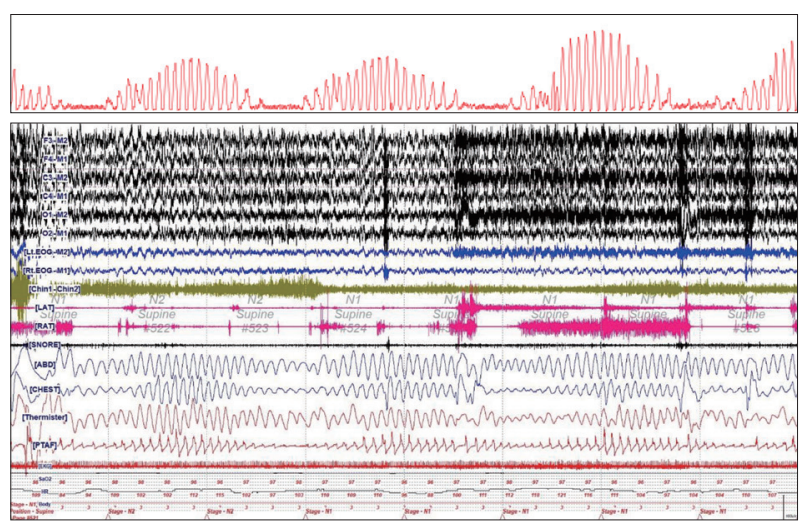

A

Figure 2. (A) A 75-year-old male with a status epilepticus and Cheyne-Stokes respiration in an intensive care unit. (B) A 42-year-old male with an ischemic stroke and obstructive sleep apnea in an intensive care unit. They underwent a polysomnography afterwards and characteristic figures of respiratory signal and polysomnographic data for four minutes are presented, respectively.

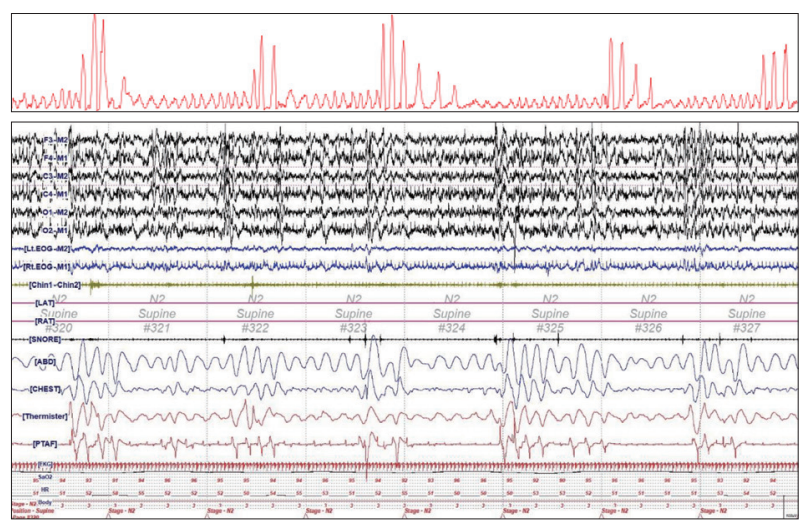

B 
Table 2. Cases with poor outcome according to CSR in each diagnosis

\begin{tabular}{lcrr}
\hline \multicolumn{1}{c}{ Diagnosis } & Poor outcome in CSR & Poor outcome in no CSR & $p$ \\
\hline Neurovascular disease (\%) & $79 / 135(58.5)$ & $45 / 138(32.6)$ & $<0.001^{*}$ \\
Non neurovascular disease (\%) & $14 / 31(45.2)$ & $25 / 102(24.5)$ & $0.041^{*}$ \\
$\quad$ Infection/inflammation (\%) & $9 / 18(50.0)$ & $11 / 48(22.9)$ & $0.041^{*}$ \\
Seizure (\%) & $4 / 10(40.0)$ & $9 / 43(20.9)$ & 0.237 \\
Cord/nerve/muscle (\%) & 0 & $4 / 7(57.1)$ & $\mathrm{u} / \mathrm{a}$ \\
Metabolic/toxic/neoplasm (\%) & $1 / 3(33.3)$ & $1 / 4(25.0)$ & $>0.999$ \\
\hline
\end{tabular}

*statistical significance $(p<0.05)$. CSR: Cheyne-Stokes respiration, u/a: unavailable

Table 3. Univariate and multivariable analysis of risk factors for poor outcome

\begin{tabular}{|c|c|c|c|c|c|c|c|c|}
\hline \multirow{2}{*}{ Parameter } & \multicolumn{4}{|c|}{ Univariate analysis } & \multicolumn{4}{|c|}{ Multivariable analysis } \\
\hline & $\mathrm{n}$ & OR & $95 \% \mathrm{CI}$ & $p$ & $\mathrm{n}$ & OR & $95 \% \mathrm{CI}$ & $p$ \\
\hline CSR & $166 / 406$ & 3.09 & $2.05-4.68$ & $<0.001$ & $139 / 281$ & 2.27 & $1.25-4.14$ & $0.007^{*}$ \\
\hline OSA & $142 / 406$ & 1.00 & $0.66-1.52$ & $>0.999$ & - & - & - & - \\
\hline Age, year ${ }^{\dagger}$ & 406 & - & - & $<0.001$ & 281 & 1.01 & $0.99-1.04$ & 0.201 \\
\hline Sex, female & $145 / 406$ & 1.84 & $1.22-2.79$ & 0.004 & $177 / 281$ & 2.42 & $1.40-4.21$ & $0.002^{*}$ \\
\hline Hypertension & $212 / 406$ & 2.11 & $1.41-3.17$ & $<0.001$ & $171 / 281$ & 1.00 & $0.56-1.77$ & 0.999 \\
\hline Diabetes & $103 / 406$ & 2.07 & $1.32-3.25$ & 0.002 & $81 / 281$ & 1.43 & $0.78-2.61$ & 0.250 \\
\hline Coronary artery disease & $24 / 406$ & 3.20 & $1.34-7.66$ & 0.009 & $22 / 281$ & 2.23 & $0.71-6.94$ & 0.168 \\
\hline Atrial fibrillation & $89 / 406$ & 1.83 & $1.14-2.94$ & 0.014 & $84 / 281$ & 0.86 & $0.47-1.59$ & 0.634 \\
\hline Heart failure & $29 / 281$ & 2.25 & $1.02-4.97$ & 0.048 & $29 / 281$ & 1.57 & $0.62-3.97$ & 0.337 \\
\hline Lung disease & $27 / 406$ & 1.03 & $0.46-2.27$ & $>0.999$ & - & - & - & - \\
\hline Previous stroke & $76 / 406$ & 1.87 & $1.13-3.09$ & 0.019 & $49 / 281$ & 1.27 & $0.63-2.55$ & 0.497 \\
\hline Neurodegenerative disease & $26 / 406$ & 2.14 & $0.96-4.78$ & 0.065 & $14 / 281$ & 1.19 & $0.36-3.93$ & 0.775 \\
\hline Diagnosis (vascular disease) & $273 / 406$ & 2.00 & $1.29-3.12$ & 0.002 & $238 / 281$ & 0.78 & $0.37-1.65$ & 0.521 \\
\hline APACHE-II score $^{\dagger}$ & 406 & - & - & $<0.001$ & 281 & 1.02 & $0.98-1.06$ & 0.304 \\
\hline
\end{tabular}

*statistical significance $(p<0.05)$ in multivariable analysis, ${ }^{\dagger}$ statistical analysis of age and APACHE-II score as continuous variables used ttest in univariate analysis and exponential (beta) for OR in multivariable analysis. OR: odds ratio, CI: confidence interval, CSR: CheyneStokes respiration, OSA: obstructive sleep apnea, APACHE-II: acute physiology and chronic health evaluation-II

의 비율이 커지는 경향을 보였다. LF/HF는 CSR과 OSA가 모두 안정호흡에 비해 컸으나 둘 사이의 통계적인 차이는 없 었다.

\section{고 찰}

본 연구는 중환자실에 입원한 신경계 질환 환자를 대상으 로 CSR을 최초로 확인했다. 가능한 모든 환자에 대해 분석 하기 위해 중환자실의 생체신호 감시장치에서 얻은 빅데이 터를 이용했다는 장점이 있다. 그 결과 신경계 중환자에서 $\mathrm{CSR}$ 의 빈도가 약 $41 \%$ 정도로 높으며 불량한 예후와 승산비 약 2.3의 유의한 관계가 있음을 보였다.

본 연구 결과인 약 $41 \%$ 의 CSR의 빈도는 Richards 등의 심 혈관질환 중환자를 대상으로 한 연구에서 확인한 $34 \%$ 와 유 사하다. ${ }^{11}$ 본 연구에 포함된 신경계 전체 중환자 중 약 $2 / 3$ 정
도의 환자가 뇌혈관질환 중환자로 심혈관질환 중환자와 위 험인자들을 공유하기 때문에 유사한 결과를 보였다고 판단 된다. Richards 등의 연구는 수면다원검사를 하룻밤 동안 시 행하여 CSR의 여부를 확인하였는데, ${ }^{11}$ 무호흡/저호흡을 모 두 CSR로 판단한 본 연구와 달리 무호흡이 있는 경우만 CSR 로 판단하였다는 차이점이 있다. Van den Broecke 등의 연 구와 Tinoco 등의 연구에서는 각각 심혈관질환 중환자와 일 반적인 중환자를 대상으로 수면다원검사 및 심전도 신호로 부터 CSR 및 주기적 호흡 여부를 확인하였고 모두 $80 \%$ 이 상의 높은 빈도를 보였다. ${ }^{12,13}$ 연구에서 사용된 CSR의 정의가 상대적으로 단순하며 CSR의 횟수에 대한 고려가 없었다는 것이 본 연구에 비해 높은 CSR 빈도를 보인 원인으로 판단 된다.

이와 같이 $\mathrm{CSR}$ 의 유병률은 조사 집단과 방법에 따라 큰 차이를 보인다. 일반 인구에서 CSR의 유병률은 $0.4 \%$ 정도로, 
Table 4. HRV analysis according to the occurrence of CSR or OSA in 23 patients, respectively

\begin{tabular}{|c|c|c|c|c|c|}
\hline HRV parameter & $\begin{array}{c}\text { Normal breathing } \\
\text { in no CSR nor OSA }\end{array}$ & $\begin{array}{c}\text { Stable breathing } \\
\text { in CSR or OSA }\end{array}$ & CSR & OSA & $\begin{array}{c}p \\
\text { (CSR vs. OSA) }\end{array}$ \\
\hline \multicolumn{6}{|l|}{ Time domain } \\
\hline Mean HR (/min) & $68.7 \pm 17.0$ & $76.1 \pm 27.4$ & $67.6 \pm 18.5$ & $75.8 \pm 22.1$ & 0.178 \\
\hline Mean NN (ms) & $930.4 \pm 247.5$ & $874.7 \pm 277.8$ & $967.5 \pm 327.6$ & $844.6 \pm 205.2$ & 0.134 \\
\hline SDNN (ms) & $37.1 \pm 37.0$ & $45.6 \pm 53.0$ & $69.6 \pm 57.9^{*}$ & $49.8 \pm 26.4$ & 0.143 \\
\hline RMSSD (ms) & $37.0 \pm 37.1$ & $35.7 \pm 33.6$ & $47.9 \pm 42.3$ & $25.9 \pm 17.0$ & $0.026^{\ddagger}$ \\
\hline pNN50 (\%) & $13.2 \pm 20.5$ & $12.5 \pm 20.0$ & $18.7 \pm 24.3$ & $6.7 \pm 11.0$ & $0.037^{\ddagger}$ \\
\hline \multicolumn{6}{|l|}{ Frequency domain } \\
\hline Total power (log scale, $\mathrm{ms}^{2}$ ) & $7.14 \pm 1.67$ & $7.28 \pm 2.03$ & $8.22 \pm 2.17$ & $7.88 \pm 1.52$ & 0.219 \\
\hline VLF (log scale, $\left.\mathrm{ms}^{2}\right)$ & $5.84 \pm 1.35$ & $5.99 \pm 1.80$ & $7.30 \pm 1.92^{* \dagger}$ & $7.10 \pm 1.19^{* \dagger}$ & 0.070 \\
\hline LF (log scale, $\mathrm{ms}^{2}$ ) & $5.34 \pm 1.86$ & $5.62 \pm 2.26$ & $6.37 \pm 2.33$ & $5.86 \pm 1.59$ & 0.260 \\
\hline HF (log scale, $\mathrm{ms}^{2}$ ) & $6.13 \pm 2.09$ & $6.52 \pm 2.64$ & $6.14 \pm 2.42$ & $6.03 \pm 2.17$ & 0.546 \\
\hline $\operatorname{VLF}(\%)$ & $35.6 \pm 25.3$ & $36.5 \pm 25.2$ & $49.6 \pm 28.8$ & $57.2 \pm 28.8^{* \dagger}$ & 0.373 \\
\hline LF (\%) & $18.3 \pm 10.1$ & $22.0 \pm 11.1$ & $19.6 \pm 12.9$ & $16.6 \pm 11.0$ & 0.397 \\
\hline $\mathrm{HF}(\%)$ & $42.4 \pm 25.7$ & $41.3 \pm 22.4$ & $30.6 \pm 23.8$ & $26.0 \pm 25.2^{* \dagger}$ & 0.521 \\
\hline $\mathrm{LF} / \mathrm{HF}$ & $0.86 \pm 0.95$ & $0.87 \pm 0.80$ & $1.78 \pm 2.55^{\dagger}$ & $1.47 \pm 1.64^{\dagger}$ & 0.630 \\
\hline
\end{tabular}

Frequency power is expressed as a natural logarithmic value or as a percentage of the total power. ${ }^{*} p<0.05$ when compared to normal breathing observed in patient without CSR nor OSA, ${ }^{\dagger} p<0.05$ when compared to stable breathing observed in patients with CSR or OSA, Istatistical significance $(p<0.05)$. HRV: heart rate variability, CSR: Cheyne-Stokes respiration, OSA: obstructive sleep apnea, HR: heart rate, SDNN: standard deviation of NN interval, RMSSD: root mean square of the successive differences, pNN50: proportion of successive RRI >50 ms in relation to the total RRI, VLF: very low frequency, LF: low frequency, HF: high frequency, RRI: RR intervals

$\mathrm{OSA}$ 의 $0.9 \%$ 보다 낮은 편이다. ${ }^{24}$ 메타 분석 결과 뇌졸중과 일 과성허혈발작 환자에서는 CSA 또는 CSR의 빈도가 약 $7 \%$ 정도로 확인되었다. ${ }^{25}$ 최근 급성 뇌경색 환자에서 시행한 국 내 두 연구에서는 모두 19\%의 CSR 빈도를 보였다. ${ }^{15,26}$ 본 연 구에서 뇌혈관질환 환자를 따로 떼어 CSR의 빈도를 분석하 면 약 49\%(135/273)로 확인되며 이는 기존 연구들에 비해 다 소 높은 편이다. 이러한 빈도의 차이는 중환자실 치료를 필요 로 하는 뇌혈관질환의 경우 $\mathrm{CSR}$ 을 일으킬 정도로 광범위한 뇌병변을 일으켰을 가능성이 높기 때문일 것이며, 그와 함께 $\mathrm{CSR}$ 의 원인이 되는 혈역학 변화를 초래하는 여러 집중 치료 와 합병증이 원인으로 판단된다., ${ }^{3,4}$

본 연구에서 인구학적인 정보와 기저 질환을 보정했을 때 $\mathrm{CSR}$ 이 있는 신경계 중환자는 그렇지 않은 환자에 비해 불량 한 예후가 발생할 가능성이 약 2.3 배 높았다. CSR은 심부전 환자에서 예후와 관련성이 잘 알려져 있다. ${ }^{27,28}$ 신경계 질환 중 뇌졸중에서 CSR의 예후에 대해서는 몇몇 연구가 있었다. Rowat 등은 138 명의 뇌졸중 환자에서 증상의 중증도를 포함 한 변수를 보정했을 때 $\mathrm{CSR}$ 이 3 개월째 예후 $(\mathrm{mRS} \geq 3)$ 와 관 계가 있음을 다중회귀분석으로 보인 바 있다. ${ }^{29}$ 하지만 Siccoli 등은 74 명의 뇌경색 환자를 대상으로 한 연구에서 CSR의 정 도와 퇴원 시 $\mathrm{mRS}$ 사이에 통계적인 유의성을 발견하지 못 하였고, 그 원인은 환자 수와 추적 기간의 차이로 해석하였
다. ${ }^{14}$ 또한 국내 뇌경색 환자 연구에서 CSR은 변수 보정 이후 예후와의 관계가 유의하지 않았는데, 이는 CSR이 뇌졸중의 결과로 작용했거나, 처음부터 심한 뇌졸중에 동반되었기 때 문일 수 있을 것으로 해석하였다. ${ }^{26}$ 이러한 과거 연구들과 비 교했을 때 본 연구에서는 뇌혈관질환을 다수 포함한 신경계 중환자의 예후와 CSR과의 통계적 유의성이 다른 변수들 보 정 이후에도 분명했는데, 중환자실 치료를 요하는 중증 환자 에서는 CSR이 증상의 악화 요인으로 작용했을 것으로 판단 할 수 있다. 중환자실 치료 중 환자의 악화 요인은 심혈관계 를 포함한 혈역학적 상태와 함께 자율신경계 기능이 중요하 고, ${ }^{30,31}$ 이러한 점이 과거 연구와 일부 다른 결과를 보인 차이 점으로 판단된다. 뇌졸중 이외의 신경계 질환에서는 CSR과 예후와의 관계가 잘 알려져 있지 않은데, 본 연구 결과 뇌혈 관질환 외의 진단에 대해서도 CSR이 예후와 관계 있었으며, 이에 대해 더 많은 수의 환자군 연구가 필요하겠다. 본 연구 에서는 또한 여성이 불량한 예후와 관련이 있었다. 남성과 여성의 임상 정보는 여성의 평균 연령이 높다는 점 이외에 기저 질환에 큰 차이가 없어, 젊은 남성과 고령인 여성의 예 후의 차이가 반영된 결과로 판단된다.

$\mathrm{HRV}$ 분석에서 $\mathrm{CSR}$ 은 OSA와 구분되는 변수 특성을 보였 다. 시간 영역 변수인 RMSSD와 $\mathrm{pNN50}$ 은 안정호흡에 비해 $\mathrm{CSR}$ 은 증가했고 $\mathrm{OSA}$ 는 감소했는데, 이는 $\mathrm{CSR}$ 에서 부교감 
신경 활성도가 커지고 OSA는 반대임을 뜻한다. 통계적으로 는 유의하지 않았으나 CSR에서 $\mathrm{NN}$ 간격이 커지고 $\mathrm{NN}$ 간 격의 표준편차는 증가하는 경향을 보였는데 이는 느린 맥박 과 함께 심박 변동이 불규칙했다는 것을 의미한다. CSR과 $\mathrm{OSA}$ 에서 HRV의 시간 영역 변수들의 변화는 과거 연구와 다른 결과를 보였는데, 기존 연구는 본 연구와 달리 심부전 환자만 대상으로 했다는 차이 때문으로 판단된다. ${ }^{22}$ 주파수 영역 분석에서는 부교감신경 조절을 반영하는 $\mathrm{HF}$ 대역 파 워가 안정호흡에 비해 둘 모두 감소하였는데 OSA에서 더 감 소폭이 컸다. VLF 대역의 증가는 CSR이나 OSA의 호흡 진 동으로부터 영향 받는 것으로 알려졌다. ${ }^{22,32}$ 교감신경과 부교 감신경을 모두 반영하는 LF는 CSR에서 더 증가했으나 통계 적으로 유의하지는 않았으며, 교감신경 활성도로 해석되는 $\mathrm{LF} / \mathrm{HF}$ 는 둘 모두 유의하게 증가했고 CSR의 변화가 더 컸 다. 기존 연구들에서도 같은 경향의 주파수 영역 변화를 보 인 바 있다. ${ }^{33,34}$ 종합하면 CSR은 부교감신경과 교감신경이 모두 활성화되는 결과로 해석할 수 있겠으며 OSA는 교감신 경이 주로 활성화되는 것으로 판단할 수 있겠다. 이와 같은 $\mathrm{HRV}$ 의 변화는 혈역학적 변화와 연관되며 심부전 환자에서 는 불량한 예후와 관계가 높음이 알려졌다. ${ }^{35,36}$

본 연구는 몇 가지 제한점이 있다. 첫 번째로는 신경계 질 환의 중증도가 고려되지 않았다는 점이다. 특히 환자의 다수 를 차지하는 뇌졸중의 정도나 뇌병변 범위에 대한 고려가 없었으며, 향후 연구에서는 질환별 중증도에 대한 고려가 필 요하겠다. 두 번째로는 호흡 신호의 획득과 시각적 해석에 대한 본질적인 한계점이다. 심전도 전극에서 얻어진 임피던 스를 통한 흥곽 호흡 신호만 이용했기 때문에 표준의 수면다 원검사에 비해 정확도가 떨어질 것이며, 두 검사 방법에 대 한 검증 연구가 없었다는 한계가 있다. 호흡 곡선 혹은 심전 도 유래 호흡을 이용한 CSR 또는 OSA를 판단하는 방법에 대해 몇몇 연구가 있으나, ${ }^{13,19,20,37}$ 임상에서 검증은 아직 부족 한 것이 사실이다. 이러한 한계점은 호흡 곡선이 판단 기준에 가장 중요한 CSR에 비해, 구강 호흡 신호와 산소포화도가 중요한 OSA에서 더 크게 작용했을 것으로 판단된다. 또한 CSR에 대한 정량화에 어려움이 있어 정량적 무호흡/저호흡 수치와 비교도 이루어지지 않았다. 이와 함께 수면 단계에 대한 고려도 현재 중환자 생체신호 데이터만으로는 어렵다 는 단점이 있다. 마지막 제한점은 호흡에 영향을 미치는 약 물에 대해 고려하지 못하였다는 점이다. 중환자실에서 주로 투여되는 베타 차단제 등의 심혈관계 약물 및 진정제 등의 신경계 약물이 환자의 호흡에 영향을 주었을 가능성이 있으 며 이에 대해서는 추가 분석이 필요하겠다.

이와 같은 한계점에도 불구하고 본 연구는 신경계 중환자
에서 CSR의 빈도를 최초로 확인했고 불량한 예후의 예측인 자로 활용될 수 있음을 보였다. 임상에서 CSR을 중환자 생체 신호 데이터를 통해 빠르게 확인하고 필요 시 교정하는 것이 예후에 도움이 될지 향후 연구가 필요하겠다.

\section{Acknowledgments}

This study was supported by the Research Grant of Korean Sleep Research Society in 2019.

\section{Conflicts of Interest}

The authors have no potential conflicts of interest to disclose.

\section{ORCID iDs}

Tae-Joon Kim Dukyong Yoon Jung Hwan Kim Jong-Hwan Jang https://orcid.org/0000-0001-8451-6634 https://orcid.org/0000-0003-1635-8376 https://orcid.org/0000-0001-8925-2850 https://orcid.org/0000-0003-3392-822X

\section{Author Contributions}

Conceptualization: Tae-Joon Kim. Data curation: Tae-Joon Kim, Jung Hwan Kim, Jong-Hwan Jang. Formal analysis: Tae-Joon Kim. Investigation: Tae-Joon Kim, Dukyong Yoon. Supervision: Tae-Joon Kim. Writing_original draft: Tae-Joon Kim. Writing_review \& editing: Tae-Joon Kim, Dukyong Yoon.

\section{REFERENCES}

1. AlDabal L, BaHammam AS. Cheyne-Stokes respiration in patients with heart failure. Lung 2010;188:5-14.

2. Javaheri S, Dempsey JA. Central sleep apnea. Compr Physiol 2013;3:141163.

3. Flinta I, Ponikowski P. Relationship between central sleep apnea and Cheyne-Stokes respiration. Int J Cardiol 2016;206 Suppl:S8-S12.

4. Herkenrath SD, Randerath WJ. More than heart failure: central sleep apnea and sleep-related hypoventilation. Respiration 2019;98:95-110.

5. Brack T, Thüer I, Clarenbach CF, et al. Daytime Cheyne-Stokes respiration in ambulatory patients with severe congestive heart failure is associated with increased mortality. Chest 2007;132:1463-1471.

6. Cowie MR, Woehrle H, Wegscheider K, et al. Adaptive servo-ventilation for central sleep apnea in systolic heart failure. N Engl J Med 2015; 373:1095-1105.

7. Magalang UJ, Pack AI. Adaptive servo-ventilation for central sleep apnea in heart failure. N Engl J Med 2016;374:691.

8. Javaheri S, Brown LK, Khayat R. CON: persistent central sleep apnea/ hunter-Cheyne-Stokes breathing, despite best guideline-based therapy of heart failure with reduced ejection fraction, is not a compensatory mechanism and should be suppressed. J Clin Sleep Med 2018;14:915-921.

9. Naughton MT. PRO: persistent central sleep apnea/hunter-CheyneStokes breathing, despite best guideline-based therapy of heart failure with reduced ejection fraction, is a compensatory mechanism and should not be suppressed. J Clin Sleep Med 2018;14:909-914.

10. Naughton MT. Cheyne-Stokes respiration: friend or foe? Thorax 2012; 67:357-360.

11. Richards KC, Anderson WM, Chesson AL Jr, Nagel CL. Sleep-related breathing disorders in patients who are critically ill. J Cardiovasc Nurs 2002;17:42-55.

12. Van den Broecke S, Jobard O, Montalescot G, et al. Very early screening for sleep-disordered breathing in acute coronary syndrome in patients without acute heart failure. Sleep Med 2014;15:1539-1546.

13. Tinoco A, Mortara DW, Hu X, Sandoval CP, Pelter MM. ECG derived Cheyne-Stokes respiration and periodic breathing are associated with 
cardiorespiratory arrest in intensive care unit patients. Heart Lung 2019; 48:114-120.

14. Siccoli MM, Valko PO, Hermann DM, Bassetti CL. Central periodic breathing during sleep in 74 patients with acute ischemic stroke-Neurogenic and cardiogenic factors. J Neurol 2008;255:1687-1692.

15. Kim Y, Kim S, Ryu DR, Lee SY, Im KB. Factors associated with CheyneStokes respiration in acute ischemic stroke. J Clin Neurol 2018;14:542548.

16. Vilella L, Lacuey N, Hampson JP, et al. Postconvulsive central apnea as a biomarker for sudden unexpected death in epilepsy (SUDEP). Neurology 2019;92:e171-e182.

17. Yoon D, Lee S, Kim TY, Ko J, Chung WY, Park RW. System for collecting biosignal data from multiple patient monitoring systems. Healthc Inform Res 2017;23:333-337.

18. Berry RB, Quan SF, Abreu AR, et al. The AASM manual for the scoring of sleep and associated events: rules, terminology and technical specifications, version 2.6. Darien: American Academy of Sleep Medicine, 2020.

19. Sadr N, de Chazal P. Comparing ECG derived respiratory signals and chest respiratory signal for the detection of obstructive sleep apnoea. 2016 Computing in Cardiology Conference (CinC);2016 Sep 11-14;Vancouver, Canada.

20. Janbakhshi P, Shamsollahi MB. Sleep apnea detection from single-lead ECG using features based on ECG-derived respiration (EDR) signals. IRBM 2018;39:206-218.

21. Varon C, Morales J, Lázaro J, et al. A comparative study of ECG-derived respiration in ambulatory monitoring using the single-lead ECG. Sci Rep 2020;10:5704.

22. Szollosi I, Krum H, Kaye D, Naughton MT. Sleep apnea in heart failure increases heart rate variability and sympathetic dominance. Sleep 2007; 30:1509-1514

23. Park KJ, Jeong H. Assessing methods of heart rate variability. Korean J Clin Neurophysiol 2014;16:49-54.

24. Donovan LM, Kapur VK. Prevalence and characteristics of central compared to obstructive sleep apnea: analyses from the Sleep Heart Health Study cohort. Sleep 2016;39:1353-1359.

25. Johnson KG, Johnson DC. Frequency of sleep apnea in stroke and TIA patients: a meta-analysis. J Clin Sleep Med 2010;6:131-137.

26. Han SH, Kim Y, Kim S, Lee SH, Lee SY. Cheyne-Stokes respiration and the outcome of acute ischemic stroke. J Sleep Med 2019;16:81-87.

27. Hanly PJ, Zuberi-Khokhar NS. Increased mortality associated with
Cheyne-Stokes respiration in patients with congestive heart failure. Am J Respir Crit Care Med 1996;153:272-276.

28. Lanfranchi PA, Braghiroli A, Bosimini E, et al. Prognostic value of nocturnal Cheyne-Stokes respiration in chronic heart failure. Circulation 1999;99:1435-1440.

29. Rowat AM, Dennis MS, Wardlaw JM. Central periodic breathing observed on hospital admission is associated with an adverse prognosis in conscious acute stroke patients. Cerebrovasc Dis 2006;21:340-347.

30. Andrews P, Azoulay E, Antonelli M, et al. Year in review in intensive care medicine, 2004. III. Outcome, ICU organisation, scoring, quality of life, ethics, psychological problems and communication in the ICU, immunity and hemodynamics during sepsis, pediatric and neonatal critical care, experimental studies. Intensive Care Med 2005;31:356-372.

31. Bento L, Fonseca-Pinto R, Póvoa P. Autonomic nervous system monitoring in intensive care as a prognostic tool. Systematic review. Rev Bras Ter Intensiva 2017;29:481-489.

32. Mortara A, Sleight P, Pinna GD, et al. Abnormal awake respiratory patterns are common in chronic heart failure and may prevent evaluation of autonomic tone by measures of heart rate variability. Circulation 1997;96:246-252.

33. Ponikowski P, Anker SD, Chua TP, et al. Oscillatory breathing patterns during wakefulness in patients with chronic heart failure: clinical implications and role of augmented peripheral chemosensitivity. Circulation 1999;100:2418-2424.

34. Rupprecht S, Hoyer D, Hagemann G, Witte OW, Schwab M. Central sleep apnea indicates autonomic dysfunction in asymptomatic carotid stenosis: a potential marker of cerebrovascular and cardiovascular risk. Sleep 2010;33:327-333.

35. Mortara A, Sleight P, Pinna GD, et al. Association between hemodynamic impairment and Cheyne-Stokes respiration and periodic breathing in chronic stable congestive heart failure secondary to ischemic or idiopathic dilated cardiomyopathy. Am J Cardiol 1999;84:900-904.

36. Lucreziotti S, Gavazzi A, Scelsi L, et al. Five-minute recording of heart rate variability in severe chronic heart failure: correlates with right ventricular function and prognostic implications. Am Heart J 2000;139: 1088-1095.

37. Maier C, Dickhaus H. Central sleep apnea detection from ECG-derived respiratory signals. Application of multivariate recurrence plot analysis. Methods Inf Med 2010;49:462-466. 